Psychological Medicine, 1986, 16, 499-501

Printed in Great Britain

\title{
EDITORIAL
}

\section{Psychiatric community care: a Maharashtrian example ${ }^{1}$}

The treatment of mental illness by native healers and religious specialists is generally acknowledged to be widespread in poor countries. However, while the healers and their methods of treatment have received considerable attention, there is little systematic information regarding the patients and their illnesses. This systematic neglect of one half of the problem dates from the early work of Lévi-Strauss (1963) and Frank (1961). Patients, if they are mentioned at all, are assumed to be women, as in Lévi-Strauss' archetypal case study (1963, pp. 186-205). As a result of this emphasis of interest little is known about the clientele of healers and healing sites. Instead, unsubstantiated assumptions abound and have acquired the status of received truths. One welcome and refreshing exception is Janzen's (1978) study of therapy in Lower Zaire. Lewis' work on spirit possession cults in east Africa has played an important part in fostering these assumptions. Lewis (1971, p. 30) describes spirit possession in Somaliland as being 'virtually restricted to women' and the typical circumstances of possession as involving "the hard-pressed wife struggling to survive and feed her children in the hard nomadic environment and liable to some degree of neglect, real or imagined on the part of her husband... and in every example I encountered some grudge against her partner was borne by the woman involved' (Lewis, 1971, pp. 75-76). Lewis' work has exerted a great influence on subsequent field-work. Time and again writers make the claim that the composition of healing cults is predominantly female. In some cases this is undoubtedly the case; in many more cases it is an unwarranted extrapolation from the genuinely female cults of affliction. Listed below are some of the writers who have assumed that healing cults cater for women's needs.

Kakar (1982, p. 61), writing about a healing temple in Rajasthan, notes that 'the temple is crowded mostly by young women'. Henry (1977, p. 309), in his article 'A North Indian healer and the sources of his power', also states that patients are generally women. Kleinman, in his study of 500 Taiwanese patients treated by shamans, tells us that more than three quarters were women, although he does point out that some come on behalf of other family members (Kleinman \& Sung, 1979). Kapferer (1983, p. 114), in his description of demonic curing rituals in Sri Lanka, reveals little about the patients except to reiterate the widely held view that "women are regarded as mentally weak in relation to men and more easily absorbed into the chaotic and destructive world of demons'. Obeyesekere (1969, p. 206), also writing about Sri Lanka, states that 'an overwhelmingly large number of patients seeking ritual remedy are females, rigid, highly repressed women with strong superegos'.

Peters (1981, p.128), in his study of shamanistic practices in the Kathmandu Valley, claims: 'The overwhelming majority of Tamang healing rituals are done for women'. Although Peters states that numerous healing rituals were observed, he gives only one case study said to be representative of the shaman's entire practice. A collection of papers on Spirit Possession in the Nepal Himalayas also adopts this general approach (Hitchcock \& Jones, 1979, p. 8): 'Unmarried women, widows and women in servant's positions are more likely to become possessed than women with children, a family and a successful marriage'. Lewis (1971, pp. 83-84) suggests that his hypothesis is equally applicable to India, even though few anthropological studies have been conducted there: "This sex-linked possession syndrome seems to be equally prevalent in India and south east Asia generally. But with the present unfortunate dearth of sociological studies on mystical affliction in those areas, in most cases this can only be inferred from brief and partial indications.'

1 Address for correspondence: Dr Vieda Skultans, Department of Mental Health, 41 St Michael's Hill, Bristol BS2 8DZ. 
The author's study of the Hindu sect of the Mahanubhavs aimed to gather some of this missing information. The Mahanubhav deity is alleged to have special powers of combatting mental illness and the site itself is reputed to have curative powers. As a result, Phaltan attracts hundreds, and at festivals thousands, of supplicants who bring with them their mentally afflicted. The afflicted come from the whole of Maharashtra state and a few from Gujerat. The temple thus serves a vast area inhabited by some 63 million people. During the period of research the temple housed 52 women and 28 men, thus seeming to support the female deprivation hypothesis. However, interviews revealed that, of the 47 families resident in the temple, 24 families had come on behalf of a man, 14 on behalf of a woman and 9 women had come alone. With the exception of these few unfortunate individuals who are middle-aged, childless or divorced, the afflicted were accompanied by at least one other family member and often by a large family contingent. There were a number of typical family units. Young men, whether married or not, were accompanied by their mothers and sometimes by their wives and young children. Young women were accompanied by their mothers, and older women by their infant children and adolescent daughters. There were no unaccompanied men in the temple, whereas a number of women had come alone. Mothers entrust the care of their young children to some other female relative in order to care for their mentally afflicted child. Women, therefore, formed the bulk of the residents because they were also the caretakers.

For these families, therefore, the affliction of one of its members has been followed by a major dislocation of family life, involving prolonged travel, loss of labour and splitting of the family. Since nearly all the inhabitants of the temple are illiterate and, therefore, unable to write letters, the move to Phaltan has entailed considerable isolation. Families arrive with no definite ideas as to how long they will stay, but with a readiness to stay until the affliction is lifted or alleviated. For some this may mean a few months and for others it may mean years. On arrival the family is assigned its sleeping quarters. Space is limited, but each family has somewhere to put its cooking pots and bedrolls.

Before joining the temple community most have had some contact with western-style psychiatric services. Those who are regarded by family and friends as mad have nearly all had considerable experience of psychiatric hospitals and psychiatrists. Treatment was discontinued either because of its high cost, or because of its ineffectiveness, or because of the difficulty of gaining admission to psychiatric hospital. One old man felt that he could not take his daughter back to the local psychiatrist because he owed him 180 rupees for an earlier course of shock treatment. For most the daily cost of psychotropic drugs was well beyond their means. Admission to psychiatric hospital was by no means a matter of course for psychotic patients. One old man complained that his daughter, who was clearly mad by any standard, behaved perfectly sanely whenever he took her to the police station. Another girl in her twenties was taken to the police station whenever her behaviour proved too much for her relatives. However, they were regularly told that they should approach the police in their own area. All the accompanied patients were there because their behaviour was perceived as bizarre, uncontrolled and sometimes violent. In contrast, the lone women had come because of depression, weakness, and physical and spiritual malaise.

Above all, the families of patients were concerned with the management and cure of their sick relatives and were not much concerned with the method of achieving this. Contrary to another popularly held assumption that the religious treatment of illness is not concerned with the removal of symptoms so much as the resolution of family or social conflicts surrounding the patient and the symbolic representation of the illness so as to facilitate its acceptance by the sick person, there were no lengthy rituals to such effect. Instead, families and their patients hoped for a cure through the simple medium of prayer and devotion.

The burden on families afflicted by mental illness was very heavy, and particularly so for women. Although each family member had come on behalf of one particular family member, illness tended to have an amoebic quality shifting between different family members. The typical pattern is for the sick person, frequently an adolescent son to be brought to the temple and a short while afterwards for the accompanying female to go into a trance. How does this transference take place? According to informants, illness is the result of witchcraft karni or possession by spirit bhut. Trance has a 
therapeutic effect in that the evil spirit which causes illness is allowed free expression, thereby providing a release of tension. Secondly, in this coming to the surface the spirit can enter into a dialogue with God and valuable information can thereby be elicited on the nature and causes of the illness. The implicit theory is that families, rather than individuals, are afflicted with a given amount of illness or misfortune. This illness is the manifestation of a spiritual affliction of the family. The disappearance of symptoms in one individual in no way signifies the end of the matter. Further manifestations of the original trouble are expected. Only when the malevolent force is withdrawn may the family expect peace and health. Many informants explicitly stated that the root cause of illness and trance are one and the same - namely, spiritual malevolence on the part of a person or bhut.

One mother of a son who had been cured of his madness described this cure as part of a continuing cycle of affliction since she was now affected by trance. Another mother of a sick girl said that, even if the girl were cured or were to die, withcraft or karni would still persist. Such explanations tend to encourage family responsibility for illness and enable particular members to take upon themselves the full brunt of the family affliction. Most often women, but on rare occasions men, pray that the family burden of illness be transferred to them. In most cases such prayers are answered in the form of both physical ill health and trance.

The supplicants at the Mahanubhav temple, therefore, differ significantly from the description of supplicants at temples in other parts of India and of the clientele of religious healers worldwide. The supplicants are not hysterical young women or women harbouring a grievance against their husband. In Phaltan women attend the temple in gratitude for past cures, in lieu of another member and to accompany a sick person. Some women when they are themselves in need of help have to come unaccompanied. All of these cases increase the numbers of women. Most often the original reason for visiting this temple is some gross disturbance of thought or behaviour in one member of the family.

Literature on psychiatric hospital admissions in poor countries has suggested that the excess of male admissions may be related to alternative indigenous sources of treatment for women. Research in Maharashtra does not support this contention. Families are more likely to come on behalf of their menfolk than their women. Women who are in need of help are frequently left to fend for themselves. However, women form the bulk of the patients' supporting network and, in so doing, are themselves drawn into the web of family affliction.

VIEDA SKULTANS

I wish to acknowledge and thank the ESRC for their generous support of my fieldwork.

\section{REFERENCES}

Frank, J. D. (1961). Persuasion and Healing. A Comparative Study of Psychotherapy. Oxford University Press: London.

Henry, E. O. (1977). A North Indian healer and the source of his power Social Science and Medicine 11, 309-317.

Hitchcock, J. T. \& Jones, R. L. (eds. ) (1976). Spirit Possession in the Nepal Himalayas. Vikas: New Delhi.

Janzen, J. M. (1978). The Quest for Therapy in Lower Zaire. University of California Press: Berkeley.

Kakar, S. (1982). Shamans, Mystics and Doctors. A Psychological Enquiry into India and its Healing Traditions. Oxford University Press: Bombay
Kapferer, B. (1983). A Celebration of Demons. Exorcism and the Aesthetics of Healing in Sri Lanka. Indiana University Press.

Kleinman, A. \& Sung, L. (1979). Why do indigenous practitioners successfully heal. Social Science and Medicine 13B, 7-26.

Lévi-Strauss, C. (1963). Structural Anthropology (transl. C. Jacobson and B. G. Schoepf). Basic Books: New York.

Lewis, I. (1971). Ecstatic Healing: An Anthropological Study of Spirit Possession and Shamanism. Penguin: Harmondsworth.

Obeyesekere, G. (1969). The ritual drama of the Sanni Demons: collective representations of disease in Ceylon. In Comparative Studies in Society and History vol. 2, pp. 174-216.

Peters, L. (1981). Ecstacy and Healing in Nepal. Undena: Malibu. 